\title{
Evaluation of Seaweed Extracts From Laminaria and Ascophyllum nodosum spp. as Biostimulants in Zea mays L. Using a Combination of Chemical, Biochemical and Morphological Approaches
}

\author{
Andrea Ertani ${ }^{1}$, Ornella Francioso ${ }^{2}$, Anna Tinti ${ }^{3}$, Michela Schiavon ${ }^{1}$, Diego Pizzeghello ${ }^{1}$ \\ and Serenella Nardi ${ }^{1 *}$ \\ ${ }^{1}$ Dipartimento di Agronomia, Animali, Alimenti, Risorse Naturali e Ambiente, Università di Padova, Padova, Italy, \\ ${ }^{2}$ Dipartimento di Scienze e Tecnologie Agro-Alimentari, Università di Bologna, Bologna, Italy, ${ }^{3}$ Dipartimento di Scienze \\ Biomediche e Neuromotorie, Università di Bologna, Bologna, Italy
}

OPEN ACCESS

Edited by:

Youssef Rouphael,

University of Naples Federico II, Italy

Reviewed by:

Santiago Sanchez-Cortes Instituto de Estructura de la Materia (IEM), Spain

Petronia Carillo,

Università degli Studi della Campania

"Luigi Vanvitelli" Caserta, Italy

${ }^{*}$ Correspondence:

Serenella Nardi

serenella.nardi@unipd.it

Specialty section: This article was submitted to

Crop and Product Physiology, a section of the journal

Frontiers in Plant Science

Received: 06 February 2018 Accepted: 20 March 2018

Published: 06 April 2018

Citation:

Ertani A, Francioso O, Tinti A,

Schiavon M, Pizzeghello $D$ and

Nardi S (2018) Evaluation of Seaweed

Extracts From Laminaria and

Ascophyllum nodosum spp. as Biostimulants in Zea mays L. Using a

Combination of Chemical,

Biochemical and Morphological Approaches. Front. Plant Sci. 9:428.

doi: 10.3389/fp/s.2018.00428
Seaweed extracts can be employed as biostimulants during crop cultivation owing to their positive effects on plant performance. Therefore, in this study one extract from Laminaria (A) and five extracts from Ascophyllum nodosum (B-F) were assayed on maize (Zea mays L.) plants supplied for 2 days with $0.5 \mathrm{~mL} \mathrm{~L}^{-1}$ of single products to evaluate their capacity to stimulate root growth and morphology, nutrition, and sugars accumulation. Firstly, extracts were chemically characterized via Fourier transform infrared $(F-I R)$ and $F T-R a m a n$ spectroscopies, and their content in carbon, nitrogen, phenolic acids and hormones (indole-3-acetic acid, IAA, and Isopentenyladenosine, IPA) was quantified. The auxin like- and gibberellic acid -like activities of all extracts were also determined. FT-IR and FT-Raman spectra provided complementary information depicting distinct spectral pattern for each extract. Bands assigned to alginic and uronic acids were dominant in FT-IR spectra, while those corresponding to polyaromatic rings were evident in FT-Raman spectra. In general, extracts stimulated root growth, nutrition, esterase activity, and sugar content. However, they showed high variation in chemical features, which may explain their different capacity in triggering physiological responses in maize. Among $A$. nodosum extracts for instance, $E$ was the most efficient in promoting root morphology traits, likely because of its elevate content in IAA ( $32.43 \mathrm{nM})$, while $F$ extract was the highest in phenol content $\left(1,933 \mathrm{mg} \mathrm{L}^{-1}\right)$ and the most successful in improving plant nutrition. On the other hand, $\mathrm{C}$ extract was very effective in stimulating root elongation, but did not influence plant nutrition. $B$ and $D$ extracts induced similar positive effects on plants, although they greatly varied in chemical composition. Laminaria extract (A) differed from A. nodosum extracts, because of its low content in total phenols and the presence of both IAA- and GA-like activity. We conclude that all seaweed extracts acted as biostimulants in maize, but their chemical properties appeared crucial in predicting the physiological response preferentially elicited by individual seaweed extracts.

Keywords: nutrition, root morphology, spectroscopy, hormones, esterase, maize, phenols 


\section{INTRODUCTION}

Consumers are increasingly appreciating the production of high quality, healthy fruits and vegetables, especially when they are obtained through a minimal impact on the environment (Spinelli et al., 2010). New approaches have been proposed to grow up the sustainability of agricultural productions and improve the quality of crops and crop-derived products. A promising tool is the use of biostimulants in the form of mixtures of substances and/or microorganisms, which are able to increase the plant nutrient use efficiency and tolerance to abiotic and biotic stresses (Colla et al., 2015; Nardi et al., 2016).

The mechanisms activated by biostimulants in plants are difficult to establish owing to the complex pool of bioactive molecules present in their formulation (Ertani et al., 2011, 2013a, 2014; Guinan et al., 2013). Studying the effects triggered by individual components might produce incorrect results when compared to those determined by the combination, and synergistic action of all constituents in the mixtures may outcome. In addition, the effects of biostimulants are not always consistent among the plant species. This is likely because plants can exhibit different sensitivity thresholds to one or more bioactive molecules (Colla et al., 2015). Also, the extraction method from the source material is critical for the maintenance of the activity of the mixture components, and different extraction procedures from the same matrix may produce more biostimulants with distinct properties and effectiveness (Godlewska et al., 2016; Michalak et al., 2016).

Among biostimulants, a special attention is given to seaweed extracts (Blunden, 1991; Cassan et al., 1992; Calvo et al., 2014). The brown seaweeds Phaeophyceae in particular, are employed in sustainable agricultural applications (Goñi et al., 2016), and some of them like Ascophyllum nodosum, Macrocystis pyrifera, and Durvillea potatorum are widely used in food and industrial applications (Khan et al., 2009). Seaweed extracts elicit an array of positive responses in plants (Prithiviraj, 2008), including the increase in growth, germination rate, chlorophyll synthesis, fruit quality, and post-harvest shelf life (Hong et al., 2007; Khan et al., 2009; Pereira et al., 2009; Calvo et al., 2014; Goñi et al., 2016). They can also induce earlier germination, flowering, and fructification (Mancuso et al., 2006; Sivasankari et al., 2006; Roussos et al., 2009; Ali et al., 2015; Satish et al., 2015), stimulate the proliferation of secondary roots (Mugnai et al., 2008; Pereira et al., 2009; Spinelli et al., 2010) and induce immunity/resistance to pathogens and abiotic stress in plants (Joubert and Lefranc, 2008; Sharma et al., 2014). Recently, the capacity of a commercial extract of Ascophyllum nodosum to alleviate drought stress in soybean via changes in physiology and expression of stress-related genes has been reported (Santaniello et al., 2017).

To date, several compounds have been identified in seaweeds as activators of plant defense mechanisms and growth promoters. Among them are: (i) polyphenols, such as phloroglucinol and its derivate eckol (Craigie, 2011; González et al., 2013, 2014; Synytsya et al., 2014; Rengasamy et al., 2015); (ii) polysaccharides, primarily alginate, fucoidan, laminaran, and carrageenans or their derived oligosaccharides (Chandía et al., 2004; Chandía and Matsuhiro, 2008; Khan et al., 2009; Craigie, 2011; González et al., 2014; Rengasamy et al., 2015); (iii) betaines, amino acids, and vitamins (MacKinnon et al., 2010); (iv) substances displaying hormone-like activity. Another valuable active component of seaweed extracts is kahydrin, a derivative of vitamin $\mathrm{K} 1$, which favors the secretion of $\mathrm{H}^{+}$ions into the apoplast (Lüthje and Böttger, 1995). This process leads to acidification of the rhizosphere, thus changing the redox state of soil and the availability of nutrients to plants.

Despite the chemical constituents of brown seaweed extracts and the physiological effects they can trigger in plants have been widely described by Battacharyya et al. (2015) with a special emphasis on horticultural crops, the comparison between several extracts with respect to their capacity to induce preferential physiological responses in plants based on the characterization of their chemical composition looks relevant in view of predicting seaweed extract specific biostimulatory effects. Therefore, this research was aimed to characterize the chemical properties and the hormone-like activity of different commercial extracts from Laminaria and Ascophyllum nodosum spp., and to explore their effects on some aspects of maize plants physiology. The main objective was to find a robust relationship between the specific properties of individual biostimulants and the physiological responses preferentially elicited, which may allow the prediction of metabolic targets for other commercial seaweed biostimulants. The choice of commercial seaweed extracts was dictated by the great variety of products that are available in the market of biostimulants, which may differ based on the algal species, and addition of chemicals or bioactive molecules during the manufacturing process.

\section{MATERIALS AND METHODS Spectroscopic Characterization of Seaweed Extracts}

Six commercially available liquid seaweed extracts, one from Laminaria spp. and five from A. nodosum spp. of North Europe origin, were used in this study. They were produced via extraction with water acidified with sulfuric acid to $\mathrm{pH} 3-3.5$. The mixtures were then centrifuged and the $\mathrm{pH}$ adjusted near neutral by addition of potassium hydroxide. Finally, the extracts were sieved through cellulosic membrane filters at $0.8 \mu \mathrm{m}$ (MembraFil ${ }^{\circledR}$ Whatman Brand, Whatman, Milano, Italy). Each extract was classified with different letters: the extract derived from Laminaria was named A, while those obtained from Ascophyllum nodosum spp. were named from B to F. Extracts were freeze-dried before performing chemical and spectroscopic analyses.

The FT-IR spectra of lyophilized extracts were recorded using an ALPHA FTIR spectrometer (Bruker Optics, Ettlingen, Germany) equipped with an ATR (attenuated total reflectance) sampling device containing diamond crystal. The absorbance spectra were collected between $4,000 \mathrm{~cm}^{-1}$ and $400 \mathrm{~cm}^{-1}$, at a spectral resolution of $4 \mathrm{~cm}^{-1}$, with 64 scans co-added and averaged. A background spectrum of air was scanned under the same instrumental conditions before each series of measurements. Spectra were processed with the Grams/386 spectroscopic software (version 6.00, Galactic Industries Corporation, Salem, NH). 
Raman spectra of lyophilized extracts were recorded in solid state with a Multiram FT-Raman spectrometer (Bruker Optics, Ettlingen, Germany) equipped with a cooled Ge-diode detector. The spectral resolution was $4 \mathrm{~cm}^{-1}$ and 6,000 scans for each spectrum were collected (integration time about $4 \mathrm{~h}$ ). The excitation source was a $\mathrm{Nd}^{3+}$-YAG laser $(1,064 \mathrm{~nm}$, about $30 \mathrm{~mW}$ laser power on the sample) in the backscattering $\left(180^{\circ}\right)$ configuration. The low laser power was due to the brown color of the samples which burned out using a higher laser power.

$\mathrm{B}$ extract in particular, appeared fluorescent and enriched in mineral content, therefore both its FT-Raman and FT-IR spectra were not comparable to the others (not shown).

\section{Determination of Total Carbon and Nitrogen, Phenols and Hormones (IAA and IPA) in Seaweed Extracts}

Carbon $(\mathrm{C})$ and nitrogen $(\mathrm{N})$ contents of seaweed extracts were determined using a dry combustion procedure inside an element analyser (vario MACRO CNS, Hanau, Germany).

Total phenols were quantified via the Folin method according to Arnaldos et al. (2001). Phenols were extracted in water/methanol $(1: 1 \mathrm{v} / \mathrm{v})$ and filtered at $0.45 \mu \mathrm{m}$. The separation of phenols was carried out with HPLC 2,700 (Thermo Finnigan, San Jose, CA, USA) coupled with an 1,806 UV/Vis (Thermo Finnigan, San Jose, CA, USA) detector. The column was a TM-LC 18 (Supelcosil) equipped with pre-column TM-LC 18 (Pelliguard, Supelco). Elution was performed at a flow rate of $1.2 \mathrm{~mL} \mathrm{~min}^{-1}$ using as mobile phase a mixture of water/ n-butanol/ acetic acid (80.5:18:1.5 v/v). The sample injection volume was $20 \mu \mathrm{L}$. Detection was performed at $275 \mathrm{~nm}$ and the identification of compounds was achieved by comparing their retention time values with those of standards (gallic, protocatetic, vanillic, caffeic, $p$-coumaric, syringic, and p-hydroxybenzoic acids (Sigma-Aldrich). The calibration curve and quantification were performed considering the relationship between peak areas vs. standard concentrations at four concentrations $(n=4)$. A linear fitting with a $\mathrm{R}$ squared $\left(R^{2}\right)=0.99$ was obtained. All reagents were of analytical grade.

Indole-3-acetic acid (IAA), an auxin, and isopentenyladenosine (IPA), a cytokinin, were determined in extracts using an enzyme-linked immuno-sorbent assay (ELISA) (Phytodetek-IAA and Phytodetek-IPA, respectively, Sigma, St. Louis, MO) as reported in Ertani et al. (2013a,b). The ELISA assay used monoclonal antibodies sensitive in the range between 0.05 and $100 \mathrm{pM}$. The tracer and standard solutions were prepared following the manufacturer's instructions, and absorbance was read at $\lambda=405 \mathrm{~nm}$ with a Biorad microplate reader (Hercules, CA). Additional details were previously reported by Schiavon et al. (2010).

\section{Hormone-Like Activities of Seaweed Extracts}

The IAA-like activity was estimated by measuring the reduction of watercress (Lepidium sativum L.) roots after treatment with either IAA or seaweed extracts, while the gibberellin-like (GAlike) activity was determined by measuring the increase in the epicotyls length of lettuce (Lactuca sativa L.) after GA and seaweed extracts application (Audus, 1972). In detail, watercress and lettuce seeds were surface-sterilized by immersion in $8 \%$ hydrogen peroxide for $15 \mathrm{~min}$. After rinsing five times with sterile distilled water, 10 seeds were placed on a sterile filter paper in a sterile Petri dish. For watercress, the filter paper was wetted with $1.2 \mathrm{~mL}$ of a $1 \mathrm{mM} \mathrm{CaSO}_{4}$ solution (control), or $1.2 \mathrm{~mL}$ of $20,10,1$, and $0.1 \mathrm{mg} \mathrm{L}^{-1}$ IAA solution (Sigma, Milan, Italy) for the calibration curve, or $1.2 \mathrm{~mL}$ of a serial dilution of seaweed extracts. For lettuce, the experimental design was the same as for watercress except that the sterile filter paper was wetted with $1.4 \mathrm{~mL}$ instead of $1.2 \mathrm{~mL}$, and the calibration curve was a progression of $100,10,1$, and $0.1 \mathrm{mg} \mathrm{L}^{-1} \mathrm{GA}$ solution (Sigma). The seeds were placed in a germination room in the dark at $25^{\circ} \mathrm{C}$. After $48 \mathrm{~h}$ for watercress and $72 \mathrm{~h}$ for lettuce, seedlings were removed and the root or epicotyl lengths measured with a TESACAL IP67 electronic caliper (TESA, Renens, Switzerland) and Data Direct software, version 1 (ArtWare, Asti, Italy). The values obtained were the means of 20 samples and five replications, with the standard errors always $5 \%$ of the mean.

Values of hormone-like activity are reported in ppm IAA and ppm GA, expressed respectively as concentration of indoleacetic acid or gibberellic acid of equivalent activity as $1 \mathrm{mg} \mathrm{C} \mathrm{L}^{-1}$.

\section{Plant Material and Growth Conditions}

Seeds of Zea mays L. (var. DK C6286, DeKalb, Padua Italy) were soaked in distilled water overnight and then surface-sterilized in $5 \%(\mathrm{v} / \mathrm{v})$ sodium hypochlorite for $10 \mathrm{~min}$, while shaking. Seeds were left to germinate for $60 \mathrm{~h}$ in the dark, at $25^{\circ} \mathrm{C}$, on a filter paper wetted with $1 \mathrm{mM} \mathrm{CaSO}_{4}$ (Ertani et al., 2011). Germinated seedlings were transplanted into $3 \mathrm{~L}$ pots containing an aerated complete culture solution, with a density of 12 plants per pot. The nutrient solution was renewed every $48 \mathrm{~h}$ and had the following composition $(\mu \mathrm{M}): \mathrm{KH}_{2} \mathrm{PO}_{4}(40), \mathrm{Ca}\left(\mathrm{NO}_{3}\right)_{2}$ (200), $\mathrm{KNO}_{3}$ (200), $\mathrm{MgSO}_{4}$ (200), FeNaEDTA (10), $\mathrm{H}_{3} \mathrm{BO}_{3}$ (4.6), $\mathrm{CuCl}_{2}$ (0.036), $\mathrm{MnCl}_{2}$ (0.9), $\mathrm{ZnCl}_{2}$ (0.09), $\mathrm{NaMoO}_{4}$ (0.01). Plants were cultivated for 14 days inside a climatic chamber with a $14 \mathrm{~h} \mathrm{light} / 10 \mathrm{~h}$ dark cycle, air temperature of $27^{\circ} \mathrm{C} / 21^{\circ} \mathrm{C}$, relative humidity of $70 / 85 \%$, and photon flux density of $280 \mathrm{~mol}$ $\mathrm{m}^{-2} \mathrm{~s}^{-1}$. Twelve days after transplant, part of plants were divided in groups and treated for $48 \mathrm{~h}$ with $0.5 \mathrm{~mL} \mathrm{~L}^{-1}$ single seaweed extracts. The remaining plants were not supplied with seaweed extracts and served as controls. Plants were randomly harvested from three pots per treatment, carefully washed and dried with blotting paper. A sub-sample of plant material was immediately frozen with liquid nitrogen and kept at $-80^{\circ} \mathrm{C}$ for further analyses of esterase activity. Another sub-sample of plant material was dried in the oven at $65^{\circ} \mathrm{C}$ and used for element and sugar quantification.

\section{Root Characteristics}

Root scanning was performed before the sampling process using an Epson Expression 10000XL 1.0 system (Regent Instruments Company, Canada) as published in Ding et al. (2014). The parameters were recorded with a root image analysis system using the software WinRHIZO: main root length ( $\mathrm{mm})$, surface 
area $\left(\mathrm{cm}^{2}\right)$, average diameter $(\mathrm{mm})$, number of tips, and length of fine roots $(\mathrm{cm})(0<\mathrm{L}<0.5)$.

\section{Elemental Composition and Soluble Sugars Determination in Maize Leaves}

Quantification of elements in leaves was obtained after acid digestion by using a microwave (Milestone Ethos model 1600, Milestone, Shelton, CT). Analytical-grade reagents provided by Merck (Merck, Darmstadt, Germany) were used to prepare all solutions. Water was purified using a Milli-Q system (18.2 M $\Omega$ $\mathrm{cm}$, Millipore, Bedford, MA). The digestions were carried out as described in Ertani et al. (2011) inside closed Teflon vessels of $120 \mathrm{~mL}$ volume using approximately $500 \mathrm{mg}$ dry leaf material and $10 \mathrm{~mL}$ of $30 \%(\mathrm{v} / \mathrm{v}) \mathrm{HCl}$. After digestion, the resulting solution was transferred and diluted with $10 \mathrm{~mL}$ ultrapure water. Elements were measured via Inductively Coupled Plasma Atomic Emission Spectroscopy (Spectrum CirosCCD, Kleve, Germany).

For analysis of reducing sugars, samples of leaf material from individual plants were dried for $48 \mathrm{~h}$ at $80^{\circ} \mathrm{C}$, ground in liquid nitrogen and then $100 \mathrm{mg}$ of each were extracted with $2.5 \mathrm{~mL}$ $0.1 \mathrm{~N} \mathrm{H}_{2} \mathrm{SO}_{4}$. Samples were incubated in a heating block for $40 \mathrm{~min}$ at $60^{\circ} \mathrm{C}$ and then centrifuged at $6,000 \mathrm{~g}$ for $10 \mathrm{~min}$ at $4^{\circ} \mathrm{C}$. After filtration $\left(0.2 \mu \mathrm{m}, \mathrm{Membra}^{\mathrm{Fil}}{ }^{\circledR}\right.$, Whatman, Milan, Italy), the supernatants were analyzed by HPLC coupled to the refractive index detector (RI) (Perkin Elmer 410, Perkin Elmer, Norwalk, CT, USA). The soluble sugars were separated through an Aminex $87 \mathrm{C}$ column $(300 \times 7.8 \mathrm{~mm}$, BioRad, Segrate, Milan, Italy) using $\mathrm{H}_{2} \mathrm{O}$ as eluent at a flow rate of $0.6 \mathrm{~mL} \mathrm{~min}^{-1}$.

\section{Esterase Enzyme Activity}

Esterase activity was performed according to Junge and Klees (1984). Leaves and roots ( $1 \mathrm{~g})$ were homogenized (1:10, w:v) in liquid $\mathrm{N}_{2}$ with $0.1 \mathrm{M}$ potassium acetate ( $\mathrm{pH} 4.0$ ) containing $0.1 \mathrm{M}$ phosphate buffer ( $\mathrm{pH} 7.0)$. The extracts were centrifuged at $15,000 \mathrm{~g}$ for $15 \mathrm{~min}$ at $2^{\circ} \mathrm{C}$ and the supernatants used as the enzyme source and expressed as a percentage of the control $(0.28$ OD $\min ^{-1}$ fresh wt $\mathrm{mg}^{-1}$ ).

\section{Statistical Analysis}

Data represent the means of measurements on tissue material derived from plants grown in three different pots per treatment. For each analysis, five plants per treatment were used ( \pm std). Analysis of variance (ANOVA) was followed by pair-wise posthoc analyses (Student-Newman-Keuls test) to determine which means differed significantly at $p<0.05$. To identify the structure of the interdependences of the main parameters studied, joint principal components analysis (PCA) was performed on the following 16 variables: main root length, root surface area, root average diameter, root number of tips, root length of fine roots, leaves elemental composition as calcium, magnesium, sulfur, iron, copper, manganese, molybdenum, zinc, boron, and leaves and roots esterase activity and 46 studied objects. The standardized variables were subjected to PCA; and the rotated orthogonal components (varimax rotation method) were extracted and the relative scores were determined. Only PCs with an eigenvalue $>1$ were considered for discussion. All statistics were made by SPSS software version 19 (SPSS inc., 1999).

\section{RESULTS}

\section{Chemical Characterization and Hormone-Like Activity of Extracts}

The main chemical features of the seaweed extracts assayed in this study are listed in Tables 1, 2. Carbon (C) content ranged from 3.7 to $12.2 \%(\mathrm{~g} / 100 \mathrm{~mL})$, while nitrogen $(\mathrm{N})$ content varied from 0.1 to $7.2 \%(\mathrm{~g} / 100 \mathrm{~mL})$ (Table 1$)$. Maximum value of IPA was measured in C extract $(8.45 \mathrm{nM})$, while E extract was particularly enriched in IAA $(32.43 \mathrm{nM})$. D extract was the least in both hormones (2.72 and 9.70 nM for IPA and IAA, respectively).

The amount of total phenols (TP) was extremely variable in the extracts (Table 2). In particular, $A$. nodosum-derived extracts were more enriched in phenols, especially $\mathrm{E}\left(1,589.4 \mathrm{mg} \mathrm{L}^{-1}\right)$ and F (1,933.8 $\left.\mathrm{mg} \mathrm{L}^{-1}\right)$, compared to the extract from Laminaria (A, $211.5 \mathrm{mg} \mathrm{L}^{-1}$ ). Among phenolic acids (gallic acid, protocatechuic acid, vanillic acid, caffeic acid, $p$-coumaric acid, syringic acid, $p$-hydroxybenzoic), $p$-hydrozybenzoic acid was dominant in all extracts, with values between $22.72 \mathrm{mg} \mathrm{L}^{-1}$ (E) and $81.11 \mathrm{mg}$ $\mathrm{L}^{-1}(\mathrm{~F})$. This phenolic compound was the unique determined in $\mathrm{C}$ extract. Syringic acid was exclusively identified in $\mathrm{F}$, while p-coumaric acid was present in both $\mathrm{A}$ and $\mathrm{B}$ extracts. Gallic acid was measured in all samples except in $C$, and its content was maximum in E extract (33.16 $\left.\mathrm{mg} \mathrm{L}^{-1}\right)$. A and $\mathrm{E}$ extracts also contained significant levels of protocatechuic, vanillic and caffeic acids.

The hormone-like activity of the extracts was evaluated via Audus test (Table 3). Only A and B extracts displayed GA-like activity (1.09E-07 ppm IAA and 1.34E-06 ppm GA). However, the IAA-like activity in these extracts was not detectable (B) or negligible (A). C extract was the highest in IAA-like activity (0.23 IAA ppm), followed by extracts F (0.11 IAA ppm), E (0.10 IAA ppm), and D (0.06 IAA ppm).

\section{Spectroscopic Characterization of Seaweed Extracts Via FT-IR and FT-Raman}

The FT-IR spectra of different seaweed extracts are shown in Figure 1. Overall, the region included within $2,500-4,000 \mathrm{~cm}^{-1}$ is not particularly discriminant, except for A extract, because it displayed very similar features: a strong $-\mathrm{OH}$ at about 3,400 $\mathrm{cm}^{-1}$ and weak $-\mathrm{CH}$ stretching bands at about $2,950 \mathrm{~cm}^{-1}$. In particular, $\mathrm{A}$ extract differed from the other extracts because the $-\mathrm{CH}$ stretching bands were not observed; moreover, three components accounting for the mineral part of this sample

TABLE 1 | Content of total carbon (C), total nitrogen (N), IPA and IAA in extracts obtained from seaweeds Laminaria (A) and Ascophyllum nodosum spp. (B-F).

\begin{tabular}{lrccc}
\hline Seaweed extract & C tot (\%) & N tot (\%) & IPA (nMol) & IAA (nMol) \\
\hline A & 4.20 & 0.40 & 4.12 & 14.6 \\
B & 3.70 & 7.20 & 4.91 & 11.61 \\
C & 4.00 & 3.50 & 8.45 & 10.39 \\
D & 12.20 & 0.30 & 2.72 & 9.70 \\
E & 5.60 & 0.10 & 5.79 & 32.43 \\
F & 3.70 & 0.10 & 3.74 & 17.79
\end{tabular}


TABLE 2 | Content of total phenols and individual phenolic acids in extracts obtained from the seaweeds Laminaria (A) and Ascophyllum nodosum spp. (B-F).

\begin{tabular}{|c|c|c|c|c|c|c|c|c|}
\hline \multirow[t]{2}{*}{ Seaweed extract } & Tot. phenols & Gallic & Protocatechuic & Vanillic & Caffeic & \multirow[t]{2}{*}{ p-Coumaric } & \multirow[t]{2}{*}{ Syringic } & \multirow[t]{2}{*}{ p-Hydroxybenzoic } \\
\hline & \multicolumn{5}{|c|}{$m g L^{-1}$} & & & \\
\hline A & 211.5 & 3.47 & 11.36 & 5.38 & 11.42 & 12.36 & n.d. & 38.81 \\
\hline B & 555.9 & 6.19 & 13.25 & 15.24 & n.d. & 21.75 & n.d. & 50.28 \\
\hline C & 900.4 & n.d. & n.d. & n.d. & n.d. & n.d. & n.d. & 58.36 \\
\hline D & $1,244.9$ & 4.97 & n.d. & 18.45 & n.d. & n.d. & n.d. & 50.15 \\
\hline$E$ & $1,589.4$ & 33.16 & 16.11 & 8.16 & 5.99 & n.d. & n.d. & 22.72 \\
\hline$F$ & $1,933.8$ & 2.90 & 1.97 & n.d. & 3.14 & n.d. & 4.94 & 81.11 \\
\hline
\end{tabular}

TABLE 3 | Hormone-like activity of extracts obtained from the seaweeds Laminaria (A) and Ascophyllum nodosum spp. (B-F).

\begin{tabular}{lcc}
\hline Seaweed extract & IAA-like activity & GA-like activity \\
\hline & $(\mathrm{ppm} \mid \mathrm{AA})$ & $(\mathrm{ppm} \mathrm{GA})$ \\
\hline A & 0.01 & $1.09 \mathrm{E}-07$ \\
B & - & $1.34 \mathrm{E}-06$ \\
C & 0.23 & - \\
D & 0.06 & - \\
E & 0.10 & - \\
F & 0.11 & - \\
\hline
\end{tabular}

IAA- and GA-like activities are expressed as ppm IAA and ppm GA, which correspond to the concentration of either indoleacetic acid or gibberellic acid of equivalent activity as $1 \mathrm{mg} C L^{-1}$.

(see below) were observed in the region 3,500-2,500 $\mathrm{cm}^{-1}$. The bands detected in the region between 1,800 and $600 \mathrm{~cm}^{-1}$ in particular, were the most characteristics for each extract, therefore they deserved a detailed description. The spectra of all extracts revealed a strong band at $1,612-1,547 \mathrm{~cm}^{-1}$ likely due to the asymmetric stretching of carboxylate vibration in alginic acid (Gómez-Ordó-ez and Rupérez, 2011), while the strong band within $1,412-1,380 \mathrm{~cm}^{-1}$ could be ascribed to the symmetric stretching vibration of the same carboxylate groups (Mathlouthi and Koenig, 1986), with the contribution of -CH and $\mathrm{C}-\mathrm{OH}$ deformation vibration. The extracts also exhibited a broad band around $1,230 \mathrm{~cm}^{-1}$ corresponding to sulfate ester groups $(\mathrm{S}=\mathrm{O})$, which is characteristic of functional groups observed in fucoidans (Gómez-Ordó-ez and Rupérez, 2011). The bands around $1,081-1,026 \mathrm{~cm}^{-1}$ could be assigned to $\mathrm{C}-\mathrm{C}-\mathrm{H}$ and $\mathrm{O}-\mathrm{C}-\mathrm{H}$ deformation, $\mathrm{C}-\mathrm{O}$ stretching, and $\mathrm{C}-\mathrm{O}$ and $\mathrm{C}-\mathrm{C}$ stretching vibrations of pyranose rings, with the contribution of mineral compounds, especially in the spectrum of sample A, whose wavenumber lies at $1,080 \mathrm{~cm}^{-1}$. On the other side, the spectra of the other samples show bands at lower wavenumbers $\left(1,025-1,030 \mathrm{~cm}^{-1}\right)$ due to carbohydrates and a shoulder at 1,080 $\mathrm{cm}^{-1}$. The band in the anomeric region between 950 and 750 $\mathrm{cm}^{-1}$ was typical of carbohydrates (Pereira et al., 2009, 2013). In particular, the band at $960 \mathrm{~cm}^{-1}$, well visible in $\mathrm{A}$ and $\mathrm{F}$ extracts, could be assigned to the $\mathrm{C}-\mathrm{O}$ stretching vibration of uronic acid residues, the one observed at $814 \mathrm{~cm}^{-1}$, evident with different intensity in all samples, likely corresponded to $\mathrm{C} 1-\mathrm{H}$ deformation vibration of mannuronic acid residues, while the one recorded at $732 \mathrm{~cm}^{-1}$ ( $\mathrm{D}$ and $\mathrm{F}$ extracts, in particular)

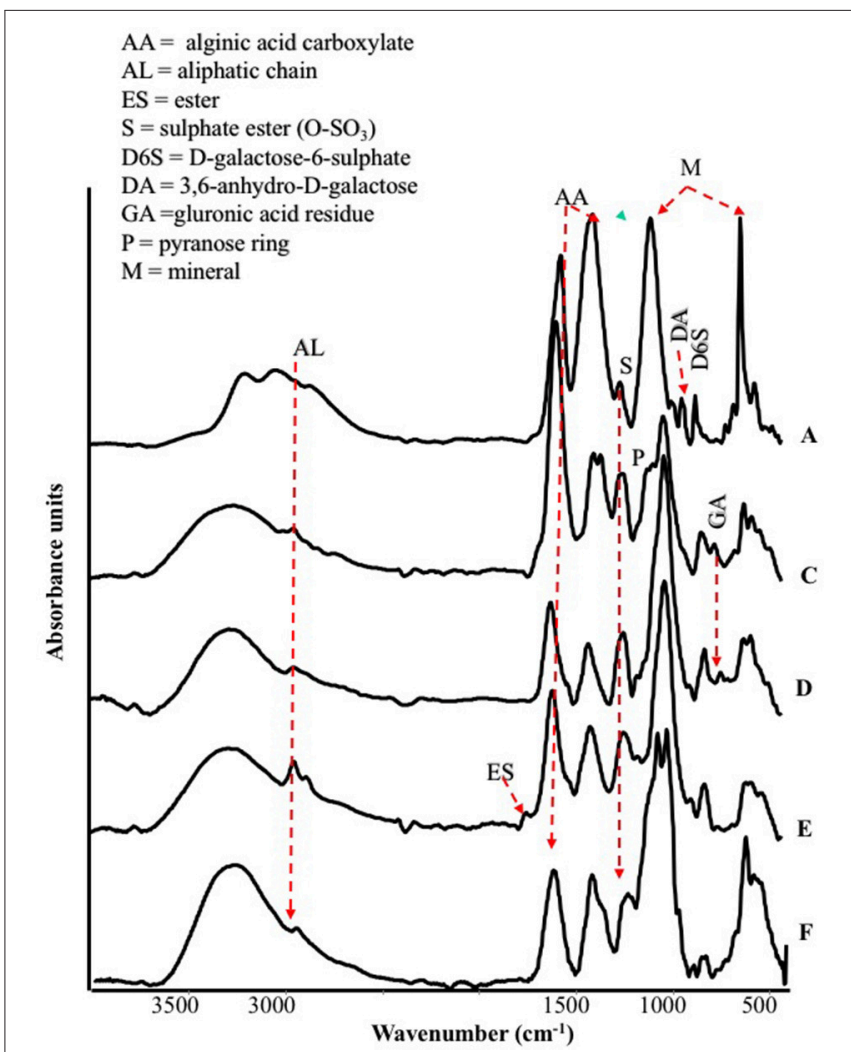

FIGURE 1 | ATR/FT-IR spectra of extracts derived from Laminaria (A) and from Ascophyllum nodosum spp. (C-F).

was characteristic of glucuronic acid residues. Going into more details, E extract was also characterized by a high content in lipids, as revealed by two sets of strong $\mathrm{C}-\mathrm{H}$ vibration at 2,930 $\mathrm{cm}^{-1}$ and $2,854 \mathrm{~cm}^{-1}$, which are the most intense in the spectra depicted in Figure 1, and the stretching vibration of carboxylic ester groups, evidenced by the band pinpointed at $1,734 \mathrm{~cm}^{-1}$ (Leal et al., 2008). Finally, the shoulder at $1,510 \mathrm{~cm}^{-1}$ was typical of aromatic rings vibration, consistently with the highest content of gallic and protocatechuic acids determined in E extract and of p-hydroxybenzoic acid in F extract (Table 2).

The spectral features of extracts were also supported by FTRaman spectra. In particular, in Figure 2 are shown, as an example, the FT-Raman spectra of two extracts (E and F). FTRaman spectra confirmed the presence of carboxylate vibration 

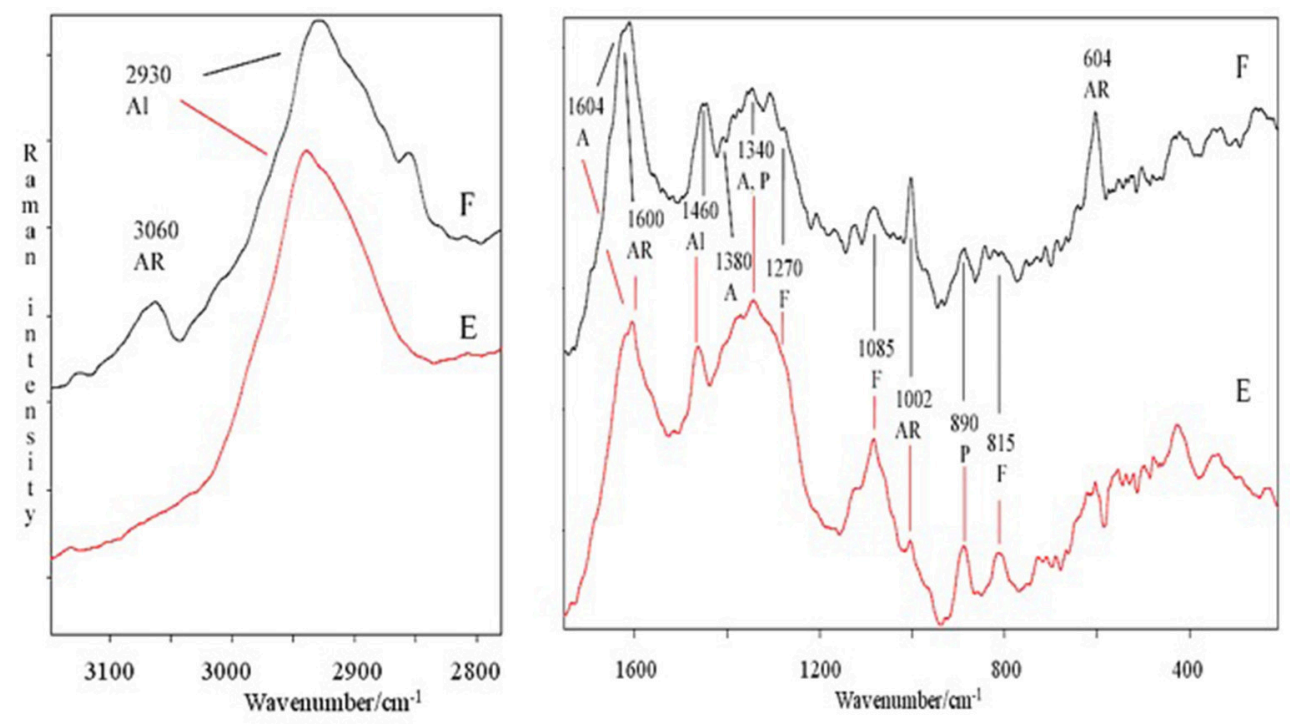

FIGURE 2 | Comparison of FT-Raman spectra of E and F extracts derived from Ascophyllum nodosum in the 3,100-2,800 and 1,700-200 cm ${ }^{-1}$ regions. Abbreviations as in Figure 1; in addition, F, fucoidans.

in alginic acid at 1,604 and 1,380-1,390 $\mathrm{cm}^{-1}$ (shoulder) (Gómez-Ordó-ez and Rupérez, 2011). Others bands at about 2,930 and $1,460 \mathrm{~cm}^{-1}$ are due to the stretching and bending vibrations of aliphatic groups. These last bands were common in $\mathrm{E}$ and $\mathrm{F}$ extracts, while only in $\mathrm{F}$ the contemporaneous presence of the bands at 3,060, about 1,600 and $1,002 \mathrm{~cm}^{-1}$ indicated a moderate/high presence of aromatic groups, due to polysubstituted aromatic compounds, as the phenolic acids reported in Table 2. The bands at $1,002 \mathrm{~cm}^{-1}$ (the most intense normally observed in the spectra of aromatic compounds) and about $1,600 \mathrm{~cm}^{-1}$ are present also in the spectrum of E extract, indicating a lower presence of total aromatics/polyaromatics, as compared to $\mathrm{F}$ extract (Table 2). The $\mathrm{E}$ extract exhibited also very intense bands at 1,085 and at about $1,270 \mathrm{~cm}^{-1}$ (shoulder) (Synytsya et al., 2014; Marinval et al., 2016) which are typical of symmetric and asymmetric stretching of sulfate groups in fucoidans, respectively, together with the band at about $815 \mathrm{~cm}^{-1}$, attributable to bending of primary C6-OS (Campos-Vallette et al., 2010; Synytsya et al., 2014). These three bands were present also in the other spectra, but with a lower intensity. Raman bands, common to both spectra, at 1,340-1,346 $\mathrm{cm}^{-1}$ were assigned to in-plane $\mathrm{CCH}, \mathrm{COH}$ and $\mathrm{OCH}$ deformations in pyranoid rings with contribution of $\mathrm{CH}_{2}$ wagging and $\mathrm{CH}_{3}$ symmetric bending of galactose and fucose, respectively (Synytsya et al., 2014). Finally, the band at about $890 \mathrm{~cm}^{-1}$ can be generically attributed to $\beta$-glycosidic bond (Marinval et al., 2016) or to $\beta$-D-terminal in mannose or glucose containing carbohydrates (Yang and Zhang, 2009).

\section{Root Growth in Response to Seaweed Extracts}

In general, root size and architecture of maize plants was positively influenced by the addition of seaweed extracts from
Laminaria and $A$. nodosum spp. (Table 4). E extract was the most successful in stimulating root elongation (plus $81 \%$ ), despite values were not significantly different from those measured for plants treated with B, C, and D extracts. Conversely, A and F extracts were the least efficient in promoting root development. In general, root surface was greater in plants supplied with seaweed extracts than in untreated plants, with maximum values measured in plants added either with $\mathrm{C}$ or $\mathrm{E}$ extract. Furthermore, plants treated with seaweed extracts, produced a higher number of root tips (plus 58 and $88 \%$ for B and E, respectively) and showed a more pronounced length of thin roots (about plus $80 \%$ for both $\mathrm{C}$ and $\mathrm{E}$ ) than the controls. An example of image comparison between roots of untreated plants (control) and plants treated with a seaweed extract is depicted in Figure 3.

\section{Effect of Seaweed Extracts on the Content of Soluble Sugars (Glucose and Fructose) in Plants}

The leaf glucose content showed great variation in response to seaweed extract application to maize plants, as shown in Table 5. Precisely, plants accumulated more glucose when treated with A, $\mathrm{B}, \mathrm{C}$, or $\mathrm{F}$ extracts, while a reduction in content of this sugar was evident in plants supplied with D or E (minus $38-40 \%$ ). In roots, the level of glucose consistently decreased in plants treated with extracts derived from A. nodosum. Conversely, it did not change in plants supplied with A extract. A different trend in fructose content was observed, being the accumulation of this sugar generally higher in both leaves and roots of plants treated with the seaweed extracts (Table 5). Only plants treated with $\mathrm{C}$ extract accumulated less fructose than control plants (minus 38 and $24 \%$ in leaves and roots, respectively). 
TABLE 4 | Root growth-associated parameters of control maize plants (untreated) and plants supplied for $48 \mathrm{~h}$ with extracts obtained from the seaweeds Laminaria (A) and Ascophyllum nodosum (B-F).

\begin{tabular}{|c|c|c|c|c|c|}
\hline Treatment & Root length (cm) & Surface $\left(\mathrm{cm}^{2}\right)$ & Diameter (mm) & Tip number & Fine root length $(\mathrm{cm})$ \\
\hline Control & $884 \pm 151 c$ & $103 \pm 20 d$ & $0.37 \pm 0.02 b$ & $1642 \pm 272 d$ & $696 \pm 129 d$ \\
\hline$A$ & $1017 \pm 64 c$ & $121 \pm 7 \mathrm{~cd}$ & $0.38 \pm 0.01 b$ & $2204 \pm 197 a$ & $835 \pm 58 c$ \\
\hline$B$ & $1432 \pm 123 a b$ & $151 \pm 13 b c$ & $0.34 \pm 0.01 c$ & $2603 \pm 142 a b$ & $1183 \pm 110 a b$ \\
\hline C & $1542 \pm 68 a$ & $175 \pm 8 a b$ & $0.36 \pm 0.01 b$ & $2318 \pm 86 b c$ & $1245 \pm 57 a$ \\
\hline D & $1422 \pm 133 a b$ & $155 \pm 18 b c$ & $0.34 \pm 0.02 c$ & $2473 \pm 228 a b$ & $1167 \pm 107 a b$ \\
\hline$E$ & $1602 \pm 140 a$ & $208 \pm 21 a$ & $0.41 \pm 0.01 a$ & $3092 \pm 297 a$ & $1266 \pm 102 a$ \\
\hline $\mathrm{F}$ & $1115 \pm 112 b c$ & $115 \pm 13 c d$ & $0.32 \pm 0.01 c$ & $1845 \pm 238 c$ & $944 \pm 88 b$ \\
\hline
\end{tabular}

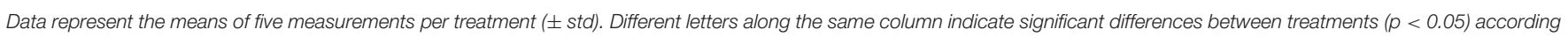
to Student-Newman-Keuls test.

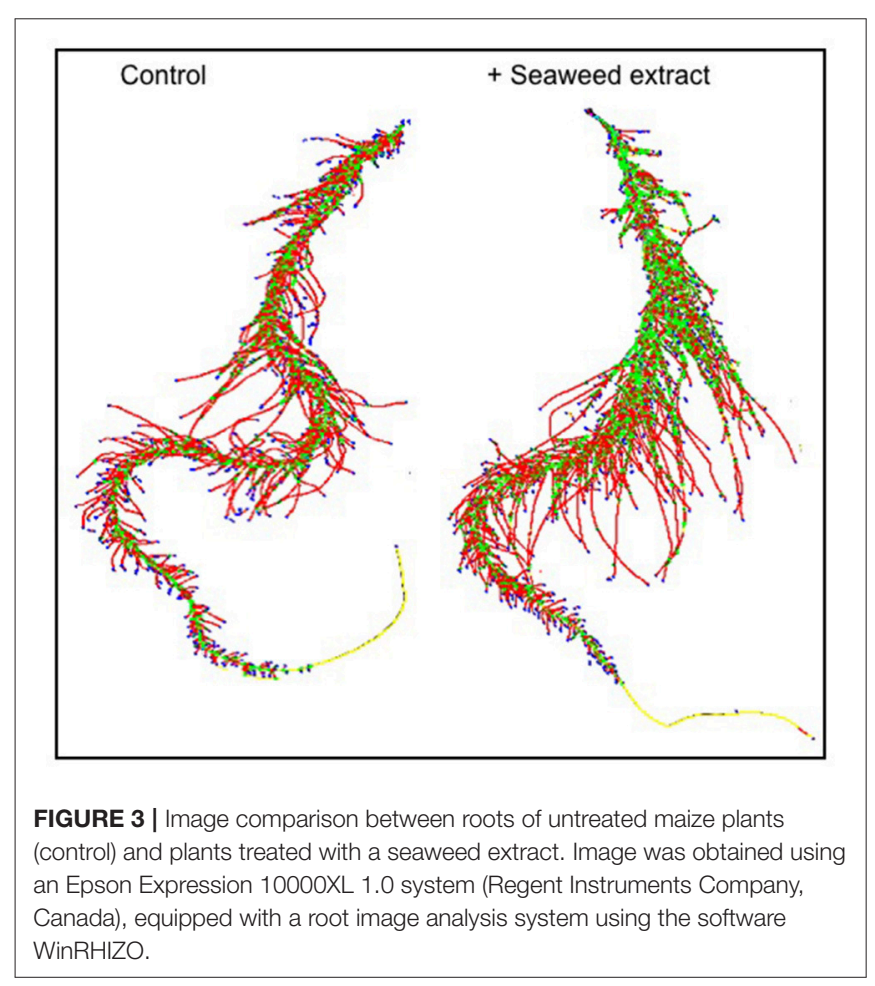

\section{Elemental Composition in Maize Leaves}

A number of elements (Ca, S, Mg, Fe, Cu, Mn, Mo, Zn, B) have been quantified in leaves of plants treated or not with the seaweed extracts (Table 6). Generally, the concentration of $\mathrm{Ca}$, $\mathrm{Mg}, \mathrm{S}$, and Mo increased in leaves after application of extracts to plants. In particular, Ca concentration was enhanced by 3 fold in plants treated with $\mathrm{D}$ and $\mathrm{F}$ extracts, while $\mathrm{Mg}, \mathrm{S}$, and $\mathrm{Mo}$ concentration increased twice in plants supplied with $\mathrm{F}$ extract. For the remaining elements analyzed, higher accumulation was observed in leaves of plants treated with certain seaweed extracts. Boron, as an example, was more accumulated in leaves of maize only after addition of $\mathrm{E}$ and $\mathrm{F}$ extracts.

Plants added with $\mathrm{C}$ extract did not shown any remarkable increase in nutrient content with the exception of $\mathrm{Cu}$, while $\mathrm{F}$ extract was the most efficient in promoting plant nutrition.
TABLE 5 | Glucose and fructose content in leaves and roots of control maize plants (untreated) and plants supplied for $48 \mathrm{~h}$ with extracts obtained from the seaweeds Laminaria (A) and Ascophyllum nodosum spp. (B-F).

\begin{tabular}{|c|c|c|c|c|}
\hline \multirow[t]{3}{*}{ Treatment } & \multicolumn{2}{|c|}{ Glucose } & \multicolumn{2}{|c|}{ Fructose } \\
\hline & \multicolumn{4}{|c|}{$m g g^{-1} d w t$} \\
\hline & Leaves & Roots & Leaves & Roots \\
\hline Control & $9.8 \pm 0.5 c$ & $29.5 \pm 1.1 \mathrm{ab}$ & $7.8 \pm 1.0 d$ & $9.7 \pm 1.2 \mathrm{bc}$ \\
\hline$A$ & $12.2 \pm 0.8 b$ & $32.1 \pm 1.3 a$ & $11.3 \pm 0.8 c$ & $9.2 \pm 1.1 \mathrm{bc}$ \\
\hline$B$ & $11.0 \pm 0.4 b$ & $24.5 \pm 1.5 b$ & $13.5 \pm 0.5 b$ & $10.9 \pm 0.4 b$ \\
\hline C & $16.1 \pm 0.8 a$ & $27.7 \pm 1.6 b$ & $4.8 \pm 0.5 e$ & $7.4 \pm 1.0 c$ \\
\hline D & $5.9 \pm 1.3 d$ & $16.7 \pm 1.3 d$ & $12.6 \pm 0.7 \mathrm{bc}$ & $10.8 \pm 0.7 b$ \\
\hline$E$ & $6.1 \pm 0.8 d$ & $26.5 \pm 1.6 b$ & $10.7 \pm 0.8 c$ & $11.8 \pm 0.7 \mathrm{ab}$ \\
\hline$F$ & $14.3 \pm 1.3 a$ & $21.6 \pm 1.8 c$ & $17.0 \pm 0.4 a$ & $13.2 \pm 1.1 \mathrm{a}$ \\
\hline
\end{tabular}

Data represent the means of five measurements per treatment ( $\pm s t d$ ). Different letters along the same column indicate significant differences between treatments $(p<0.05)$ according to Student-Newman-Keuls test.

\section{Effects of Extracts on Esterase Enzyme Activity}

The activity of esterase in leaves and roots of maize plants was increased by seaweed extracts (Figures $4 \mathbf{A}, \mathbf{B}$ ). In particular, Laminaria's extract (A) determined a more pronounced increment of esterase activity in foliar tissues than in roots (plus 38 and 78\%, respectively). Among extracts derived from A. nodosum, $\mathrm{F}$ extract appeared the most effective in promoting esterase activity (plus 112\% than the controls). In roots, extracts from A. nodosum stimulated esterase activity more than Laminaria's extract. Maximum values of percent increases in activity were measured in plants treated with B (plus 154\%) and F (plus 198\%) extracts.

\section{Principal Components Analysis}

Three factors accounted for $78.27 \%$ of the total variance. Factor 1 (PC1) explained $42.21 \%$ of the variance and was positively correlated with Mn, Fe, Mo, Ca, B, Zn (Table 7). Factor 2 explained $20.88 \%$ and was positively correlated with the esterase activity in leaves and roots and the concentration of $\mathrm{Mg}, \mathrm{Cu}$ and S (Table 7). Factor 3 explained the remaining $15.18 \%$ and was positively correlated with root parameters such as root surface, 


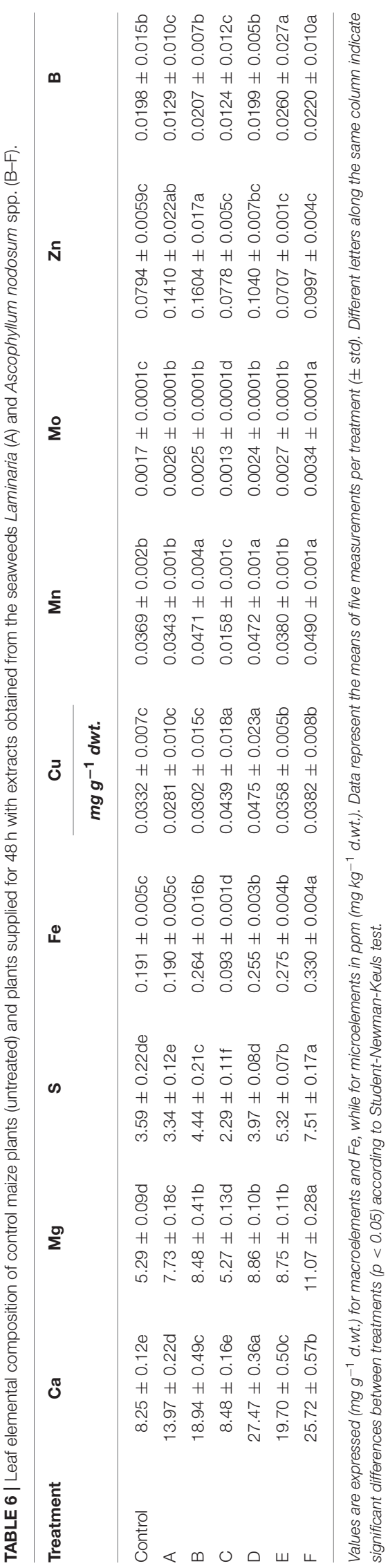

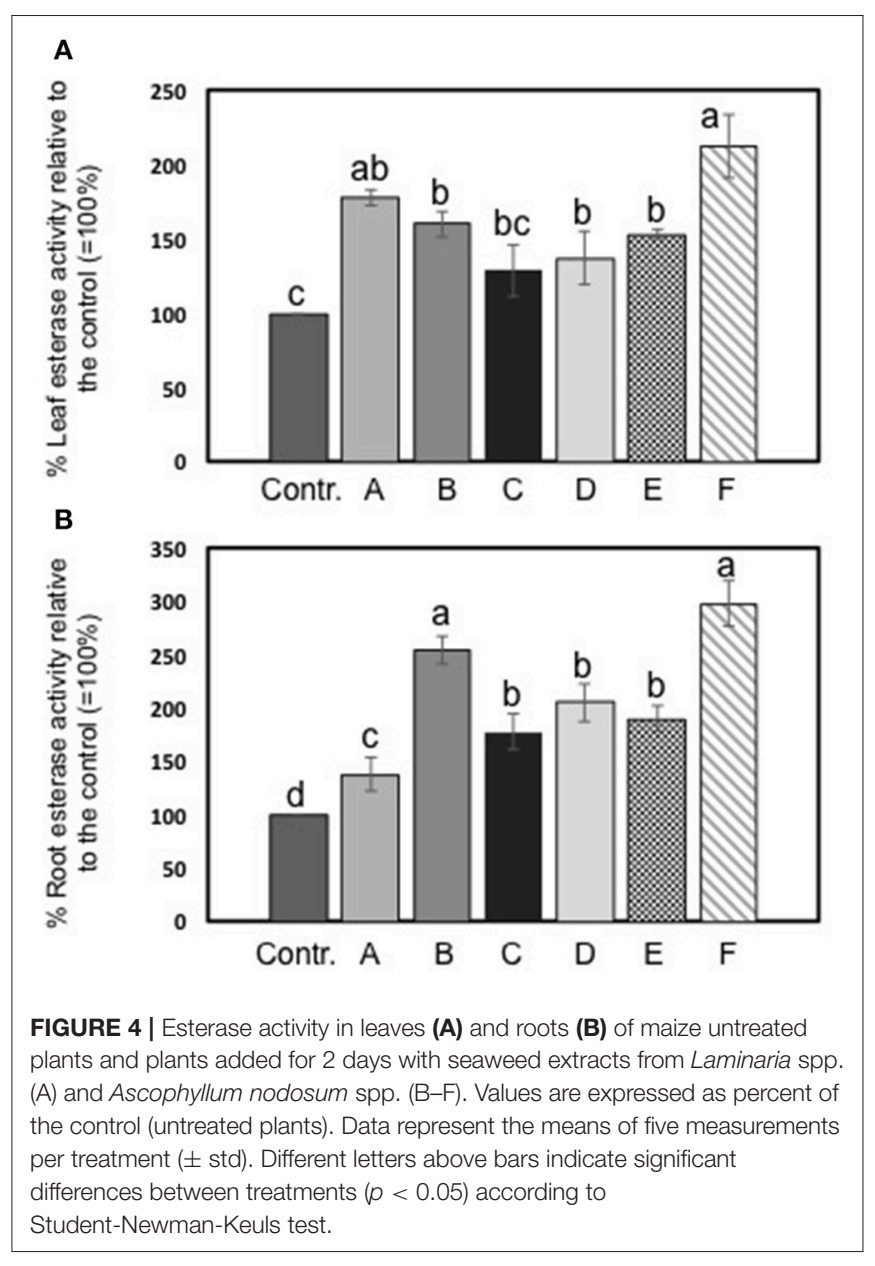

root length, fine roots, number of tips, and diameter (Table 7). Plotting data according to PC1 and PC2 (Figures 5A,B) allowed three clusters to be identified corresponding to maize plant treated with $\mathrm{C}$ extract $(=3$ in Figures 5,6$)$ and with seaweed $\mathrm{F}$ extract (=6 in Figures 5, 6) (top), while control plants $(=7$ in Figures 5, 6) and plants treated with extracts A, B, D, E $(=1,2$, 4, 5, respectively, in Figures 5, 6) scattered around the origin. In particular, plants treated with $\mathrm{F}$ extract $(=6$ in the Figures 5, 6) were characterized by high values of esterase activity and $\mathrm{Mg}$, whereas plants treated with $\mathrm{C}$ extract $(=3$ in Figures 5, 6) had low values in $\mathrm{Fe}, \mathrm{Mn}, \mathrm{Mo}$, and $\mathrm{Ca}$. From the projection of PC1 with PC3 (Figures 6A,B) it can be noted that untreated plants $(=7$ in Figures 5, 6) and plants treated with extracts A, B, D, E, F (=1, $2,4,5,6$, respectively, in Figures 5, 6) where distributed along a line, evidencing decreasing values in root surface, root length and fine roots from the upper (seaweed extracts B and E, $=2$ and 5, respectively, in Figures 5, 6) to lower (extract A and untreated, $=1$ and 7, respectively, in Figures 5, 6) samples of the cluster.

\section{DISCUSSION}

Extracts from seaweeds are rich in several bioactive compounds that might act in plants inducing an array of positive 
TABLE 7 | Loadings values of some morphometric and chemical variables on the axes identified by principal components analysis for control (untreated) maize plants and plants supplied for $48 \mathrm{~h}$ with extracts obtained from the seaweeds Laminaria (A) and Ascophyllum nodosum spp. (B-F).

\begin{tabular}{lrrr}
\hline Variable & PC1 & PC2 & PC3 \\
\hline Mn & 0.940 & 0.091 & -0.175 \\
Fe & 0.916 & 0.317 & -0.101 \\
Mo & 0.868 & 0.240 & -0.027 \\
Ca & 0.826 & 0.373 & 0.244 \\
B & 0.634 & 0.403 & 0.150 \\
Zn & 0.550 & -0.099 & -0.087 \\
EstL & 0.115 & 0.928 & -0.195 \\
EstR & 0.190 & 0.885 & -0.169 \\
Mg & 0.427 & 0.832 & 0.054 \\
S & 0.600 & 0.756 & -0.153 \\
Cu & -0.334 & 0.558 & 0.343 \\
Surface & -0.122 & -0.152 & 0.948 \\
Length & -0.046 & -0.063 & 0.946 \\
Fine & -0.122 & 0.091 & 0.903 \\
Tips & 0.153 & -0.154 & 0.820 \\
Diameter & -0.076 & -0.449 & 0.520 \\
\hline & & & \\
\hline
\end{tabular}

physiological responses, such as improved biomass production, amelioration of nutrition and resistance to stress (Engel et al., 2006). For this reason, they can be employed in agricultural practices to promote the health status of crops.

In this research, extracts from Laminaria and A. nodosum spp. were tested in maize plants to assay their biostimulant properties. Overall, they enhanced root system development and plant nutrition. The increased root growth by extracts is well evidenced by the PCA analysis, which highlighted a gradient where the untreated plants displayed the lowest values. Though, extracts revealed distinct chemical properties, which could explain their different efficacy in eliciting physiological responses related to plant growth and increased capacity to absorb nutrients (Figure S1). Differences in chemical composition of extracts could be ascribed to the algal species and, within the species A. nodosum, to different locations where the seaweeds were collected. Also, the amount of biologically active extracted compounds could vary depending on the sampling season and environmental conditions. Specifically, we found several functional groups attributable to polysaccharides (i.e., alginate or fucoidan), for which a number of biological activities have been recognized, including the stimulation of natural defense responses in plants (Hernández-Herrera et al., 2016). Spectroscopic analyses also revealed the presence of functional groups corresponding to lipids and phenols in seaweed extracts. Each type of biomolecule displayed a characteristic signal in FTIR and Raman spectra. Even though Raman spectroscopy is an emerging tool for the study of bio-macromolecules, in our study only $\mathrm{E}$ and $\mathrm{F}$ extracts showed an acceptable signal to noise ratio, while for other extracts a strong fluorescence covered completely the weak Raman signals. Diagnostic bands of polysaccharides, mainly agars and carrageenans, were well identified by using FT-IR.
Differences in chemical composition between two A. nodosum commercial biostimulants, especially in terms of phenolic compounds, were reported by Goñi et al. (2016) as well. In this case, heterogeneity was evidenced between these biostimulants based on their impacts on the Arabidopsis thaliana transcriptome.

All extracts exerted a positive effect on the activity of esterase enzyme, which is considered a marker of plant developmental processes, being involved in organogenesis and functioning as an early indicator of somatic embryogenesis (Chibbar et al., 1988; Pedersen and Andersen, 1993; Krsnik-Rasol et al., 1999; Balen et al., 2003). Esterase belongs to a group of enzymes that hydrolyse ester bonds, and occurs in several isoforms in plant and animal cells. The increase of esterase enzymes associated with wall fractions, for instance, has been proposed to be involved in the turnover of phenolic acids that are cross-linked to wall polysaccharides (Thaker et al., 1986). Therefore, higher esterase activity in maize plants treated with Laminaria and $A$. nodosum spp. extracts was indicative of their stimulatory effect on plant biomass production.

Among extracts from $A$. nodosum, E was the most effective in promoting root associated parameters (root length, surface, tip number, and fine roots), as confirmed by the PCA analysis (Figure 6) as well. This was likely because of its higher content in hormones such as auxin (IAA $=32.43 \mathrm{nM}$ ) and cytokinin (IPA $=5.79 \mathrm{nM}$ ), and intermediate values of IAA-like activity. In this respect, several studies have shown that auxins and/or substances endowed with auxin-like activity contained in seaweed extracts and other biostimulants can induce positive effects on lateral root and hair formation (Mugnai et al., 2008; Pereira et al., 2009; Schiavon et al., 2010; Spinelli et al., 2010; Ertani et al., 2013a,b).

Stimulation of root development by seaweed extracts was likely responsible of increased accumulation of several macroand micro-elements in plants, with a more pronounced effect associated to extracts derived from A. nodosum compared to Laminaria, like suggested by PCA analysis (Figures 6, 7). The increase of minerals' accumulation in plants treated with algal extracts was previously reported and explained as a result of the up-regulation of genes coding for nitrate, sulfate, and iron transporters, and/or stimulation of root cell division and lateral root/hair development (Mugnai et al., 2008; Pereira et al., 2009; Spinelli et al., 2010).

In our study, $\mathrm{F}$ extract was the most successful in enhancing the plant capacity to absorb and accumulate nutrients. This extract displayed similar intermediate values of IAA-like activity as E extract, but was not efficient in improving all root parameters. We hypothesize that the remarkable effect caused by $\mathrm{F}$ extract on plant nutrition was primarily due to enhanced transcription and/or activity of plant membrane nutrient transporters rather than to an increase in root absorption surface. It is noteworthy that $\mathrm{F}$ extract was the highest in phenol content $\left(1,933 \mathrm{mg} \mathrm{L}^{-1}\right)$. Phenols are important signaling molecules and in adequate amounts exert several positive effects in plants, even when they are exogenously applied or present in biostimulant formulations (Ertani et al., 2011). However, if their concentration is too high in the plant or in the surrounding environment, phenol compounds might become toxic to some extent, thus 

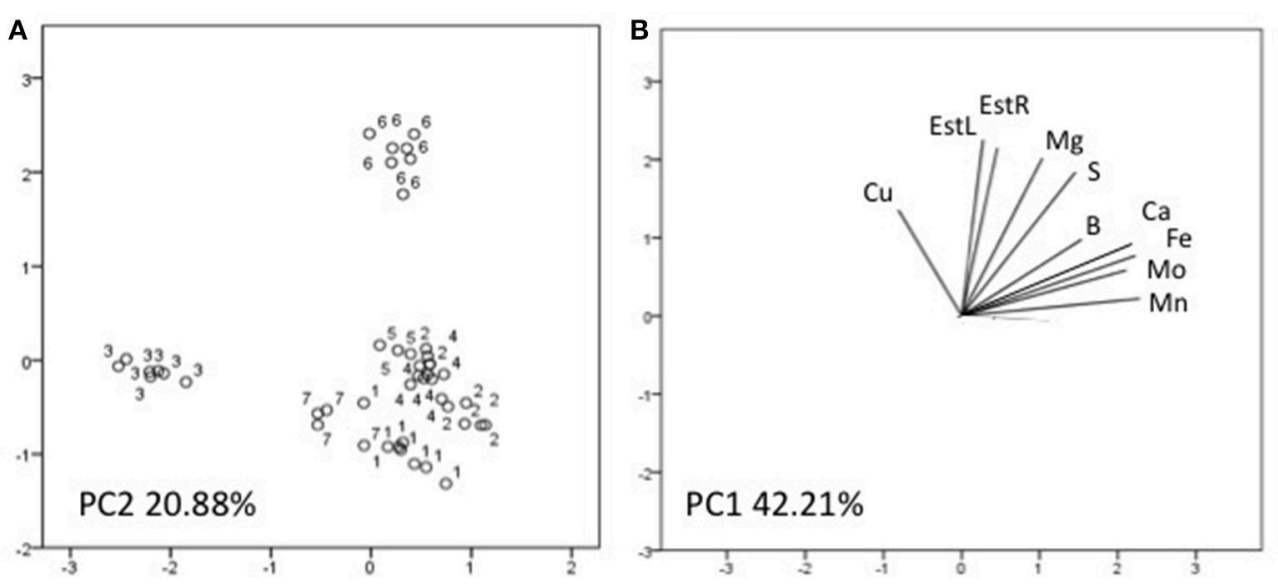

FIGURE 5 | Position of the samples representative of maize plants untreated and treated with seaweed extracts (A) and of the variables (B) projected in the plane determined by the first two principal axes of the PCA. Seaweed extracts correspond to the circle number $A=1, B=2, C=3, D=4, E=5, F=6$, and untreated plants $=7$. EstL and EstR: esterase activity in leaves and in roots, respectively.

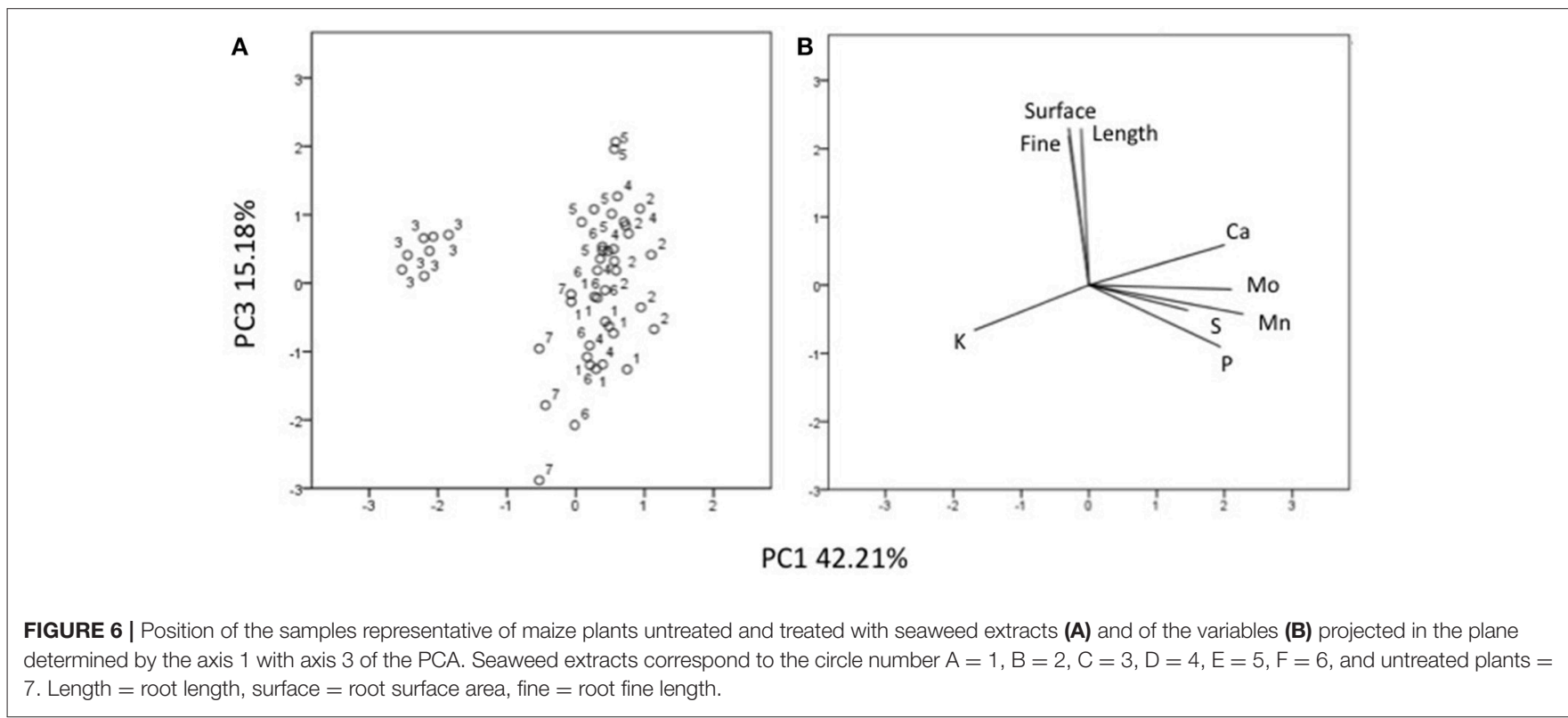

overcoming the positive effects on root growth normally exerted by substances endowed with auxin-like activity (Muscolo et al., 2013). On the other hand, extracts that are very low in total phenol content may be unable to significantly increase root development as well, regardless if they display IAA-like activity. This may be the case of A extract from Laminaria, which was the lowest in total phenols, while displaying GA-like activity (Nardi et al., 2000).

$\mathrm{B}$ and $\mathrm{D}$ extracts determined equivalent increases in root growth, despite they greatly varied in chemical composition, especially with respect to $\mathrm{N}$ content, type of hormone-like activity and phenol content. Perhaps, their similar contents in IPA and IAA could have overcome differences in the type of hormone-like activity. It is also possible that nitrogen in B extract was not all promptly available for plant absorption whether in the form of long peptides, despite some of them may function as signaling molecules (Ertani et al., 2013a,b), or other organic N compounds. $\mathrm{B}$ and $\mathrm{D}$ extracts also caused a similar accumulation of numerous of elements, with the exception of $\mathrm{Ca}, \mathrm{Cu}$ (for which $\mathrm{D}$ extract promoted higher accumulation) and $\mathrm{Zn}$ (more accumulated in plants treated with E), thus suggesting that active molecules in $\mathrm{B}$ and $\mathrm{D}$ extracts acted on both mineral nutrient transporters and growth signaling pathways, as it can be hypothesized for $\mathrm{E}$ extract.

$\mathrm{C}$ extract induced similar increases in root growth as B and D extracts, likely by virtue of its high content in IPA $(8.45 \mathrm{nM})$ and IAA-like activity. Nevertheless, it was significantly different from all other extracts, as revealed from PCA analysis (Figures 5, 6): despite the elevate IAA-like activity and its capacity to stimulate root development, apparently it did not exert any appreciable effect on plant nutrition. Even when the total content of individual nutrients in plants treated with extract $\mathrm{C}$ was 
calculated, values were lower compared to those in plants treated with the other extracts (data not shown). Therefore, while for $\mathrm{F}$ extract we hypothesized that its composition was very effective in promoting plant nutrition but not root development, in this case it is possible that the formulation of $\mathrm{C}$ extract was more successful in eliciting responses related to root growth.

C extract also caused a decrease of fructose content in plants. Fructose seems to be related to secondary metabolites production, in particular of erythrose-4-P, which acts as a substrate for lignin and phenolic compounds synthesis (Caretto et al., 2015). The other extracts determined a general increase of fructose content, especially in leaves, which may suggest their capacity to trigger the phenlylpropanoid pathway. This metabolic route has been established as one of the main target of biostimulant action in plants (Schiavon et al., 2010; Colla et al., 2015; Ertani et al., 2017) and is critical for plant development and stress conditions overcoming. On the other side, glucose content was found to increase in leaves of plants treated with the majority of extracts, while it was reduced or unaffected in roots. Glucose in plants either acts as a substrate for cellular respiration or osmolyte to maintain cell homeostasis (Rosa et al., 2009). The reduction of this sugar, especially in the roots, may be ascribed to higher consumption because of the respiration process in order to produce more ATP for active nutrient transport.

\section{CONCLUSIONS}

This study underlines a close relationship between the chemical properties of commercial seaweed extracts from Laminaria and A. nodosum spp. and select plant physiological responses they are able to positively induce. The results obtained strongly support the utility a robust chemical characterization of commercial seaweed extracts based on different approaches in predicting the metabolic targets of biostimulants in plants and could be extended to other seaweed biostimulants available in the market.

\section{AUTHOR CONTRIBUTIONS}

AE analyzed the chemical characteristics of seaweed extracts and plants, and wrote part of the manuscript, OF and AT performed the spectroscopic analyses and wrote the relative part in the manuscript, DP performed the statistical analysis, root measurements and esterase activity assay, MS wrote part of the manuscript and edited it, SN supervisioned the study.

\section{ACKNOWLEDGMENTS}

We would like to thank Dr. Piergiorgio Stevanato for kindly providing us the Epson Expression 10000XL 1.0 system for root morphology analysis, and Federica Zanellato for the precious help in performing lab experiments.

\section{SUPPLEMENTARY MATERIAL}

The Supplementary Material for this article can be found online at: https://www.frontiersin.org/articles/10.3389/fpls.2018. 00428/full\#supplementary-material

Figure S1 | Heat map of plant-associated parameters influenced by individual seaweed extracts. Different colors indicate different levels of induction $(+,++$, $+++)$, repression (-) or no effect (=).

\section{REFERENCES}

Ali, N., Farrell, A., Ramsubhag, A., and Jayaraman, J. (2015). The effect of Ascophyllum nodosum extract on the growth, yield and fruit quality of tomato grown under tropical conditions. J. Appl. Phycol. 28, 1353-1362. doi: 10.1007/s10811-015-0608-3

Arnaldos, T. L., Mu-oz, R., Ferrer, M. A., and Calderón, A. A. (2001). Changes in phenol content during strawberry (Fragaria $\mathrm{x}$ ananassa, cv. Chandler) callus culture. Physiol. Plant. 113, 315-322. doi: 10.1034/j.1399-3054.2001.113 0303.x

Audus, L. J. (1972). Plant Growth Substances. Chemistry and Physiology, Vol. 1. London: Leonard Hill Books.

Battacharyya, D., Babgohari, M. Z., Rathor, P., and Prithiviraj, B. (2015). Seaweed extracts as biostimulants in horticulture. Sci. Hortic. 196, 39-48. doi: 10.1016/j.scienta.2015.09.012

Balen, B., Krsnik-Rasol, M., and Simeon-Rudolf, V. (2003). Isoenzymes of peroxidase and esterase related to morphogenesis in Mammillaria gracillis Pfeiff. tissue culture. J. Plant Physiol. 160, 1401-1406. doi: 10.1078/0176-1617-00935

Blunden, G. (1991). "Agricultural uses of seaweeds and seaweed extracts," in Seaweed Resources in Europe: Uses and Potential, eds M. D. Guiry and G. Blunden (Chichester: Wiley), 65-81.

Calvo, P., Nelson, L., and Kloepper, J. W. (2014). Agricultural uses of plant biostimulants. Plant Soil. 383, 3-41. doi: 10.1007/s11104-014-2131-8

Campos-Vallette, M. M., Chandía, N. P., Clavijo, E., Leal, D., Matsuhiro, B., Osorio-Roman, I. O., et al. (2010). Characterization of sodium alginate and its block fractions by surface-enhanced Raman spectroscopy. J. Raman Spectrosc. 41, 758-763. doi: $10.1002 /$ jrs. 2517
Caretto, S., Linsalata, V., Colella, G., Mita, G., and Lattanzio, V. (2015). Carbon fluxes between primary metabolism and phenolic pathway in plant tissues under stress. Int. J. Mol. Sci. 16, 26378-26394. doi: 10.3390/ijms161125967

Cassan, L., Jean, I., Lamaze, J., and Morotgaudry, J. F. (1992). The effect of the Ascophylum nodosum extract Geomer GA14 on the growth of spinach. Bot. Mar. 35, 437-439. doi: 10.1515/botm.1992.35.5.437

Chandía, N. P., and Matsuhiro, B. (2008). Characterization of a fucoidan from Lessonia vadosa (Phaeophyta) and its anticoagulant and elicitor properties. Int. J. Biol. Macromol. 42, 235-240. doi: 10.1016/j.ijbiomac.2007.10.023

Chandía, N. P., Matsuhiro, B., Mejías, E., and Moenne, A. (2004). Alginic acids in Lessonia vadosa: partial hydrolysis and elicitor properties of the polymannuronic acid fraction. J. Appl. Phycol. 16, 127-133. doi: 10.1023/B:JAPH.0000044778.44193.a8

Chibbar, R. N., Schyluk, J., Georges, F., Mallard, C. S., and Constabel, F. (1988). Esterase isozymes as markers of somatic embryogenesis in cul- tured carrot cells. J. Plant Physiol. 133, 367- 370 doi: 10.1016/S0176-1617(88)80218-9

Colla, G., Nardi, S., Cardarelli, M., Ertani, A., Lucini, L., Canaguier, R., et al. (2015). Protein hydrolysates as biostimulants in horticulture. Sci. Hortic. 196, 28-38. doi: 10.1016/j.scienta.2015.08.037

Craigie, J. S. (2011). Seaweed extract stimuli in plant science and agriculture. $J$. Appl. Phycol. 23, 371-393. doi: 10.1007/s10811-010-9560-4

Ding, Y., Feng, R., Wang, R., Guo, J., and Zheng, A. (2014). Dual effect of Se on Cd toxicity: evidence from plant growth, root morphology and responses of the antioxidative systems of paddy rice. Plant Soil 375, 289-301. doi: 10.1007/s11104-013-1966-8

Ertani, A., Schiavon, M., Altissimo, A., Franceschi, C., and Nardi, S. (2011). Phenol-containing organic substances stimulate phenylpropanoid metabolism in Zea mays. J. Plant Nutr. Soil Sci. 174, 496-503. doi: 10.1002/jpln.201000075 
Ertani, A., Pizzeghello, D., Altissimo, A., and Nardi, S. (2013a). Use of meat hydrolysate derived from tanning residues as plant biostimulant. J. Plant Nutr. Soil Sci. 176, 287-295. doi: 10.1002/jpln.201200020

Ertani, A., Pizzeghello, D., Baglieri, A., Cadili, V., Tambone, F., Gennari, M., et al. (2013b). Humic-like substances from agro-industrial residues affect growth and nitrogen assimilation in maize (Zea mays L.) plantlets. J. Geochem. Exp. 129, 103-111. doi: 10.1016/j.gexplo.2012.10.001

Ertani, A., Pizzeghello, D., Francioso, O., Sambo, P., Sanchez-Cortes, S., and Nardi, S. (2014). Capsicum chinensis L. growth and nutraceutical properties are enhanced by biostimulants in a long-term period: chemical and metabolomic approaches. Front. Plant Sci. 5:375. doi: 10.3389/fpls.2014. 00375

Ertani, A., Schiavon, M., and Nardi, S. (2017). Transcriptome-wide identification of differentially expressed genes in Solanum lycopersicon L. in response to an alfalfa-protein hydrolysate using microarrays. Front. Plant Sci. 8:1159. doi: $10.3389 /$ fpls.2017.01159

Engel, S., Puglisi, M. P., Jensen, P. R., and Fenical, W. (2006). Antimicrobial activities of extracts from tropical Atlantic marine plants against marine pathogens and saprophytes. Mar. Biol. 149, 991-1002. doi: 10.1007/s00227-006-0264-x

Godlewska, K., Michalak, I., Tuhy, E., and Chojnacka, K. (2016). Plant growth biostimulants based on different methods of seaweed extraction with water. Biomed. Res. Int. 2016:5973760. doi: 10.1155/2016/5973760

Gómez-Ordó-ez, E., and Rupérez, P. (2011). FTIR-ATR spectroscopy as a tool for polysaccharide identification in edible brown and red seaweeds. Food Hydrocoll. 25, 1514-1520. doi: 10.1016/j.foodhyd.2011. 02.009

Goñi, O., Fort, A., Quille, P., McKeown, P. C., Spillane, C., and O'Connell, S. (2016). Comparative transcriptome analysis of two Ascophyllum nodosum extract biostimulants: same seaweed but different. J. Agric. Food Chem. 64, 2980-2989. doi: 10.1021/acs.jafc.6b00621

González, A., Castro, J., Vera, J., and Moenne, A. (2013). Seaweed oligosaccharides stimulate plant growth by enhancing carbon and nitrogen assimilation, basal metabolism, and cell division. J. Plant Growth Regul. 32, 443-448. doi: 10.1007/s00344-012-9309-1

González, A., Contreras, R. A., Zú-iga, G., and Moenne, A. (2014). Oligocarrageenan kappa-induced reducing redox status and activation of TRR/TRX system increase the level of indole-3-acetic Acid, gibberellin A3 and trans-zeatin in Eucalyptus globulus trees. Molecules 19, 12690-12698. doi: $10.3390 /$ molecules190812690

Guinan, K. J., Sujeeth, N., Copeland, R. B., Jones, P. W., O’Brien, N. M., Sharma, H. S. S., et al. (2013). Discrete roles for extracts of Ascophyllum nodosum in enhancing plant growth and tolerance to abiotic and biotic stresses. Acta Hortic. 1009, 127-135. doi: 10.17660/ActaHortic.2013.1009.15

Hernández-Herrera, R. M., Santacruz-Ruvalcaba, F., Za-udo-Hernández, J., and Hernández-Carmona, G. (2016). Activity of seaweed extracts and polysaccharide-enriched extracts from Ulva lactuca and Padina gymnospora as growth promoters of tomato and mung bean plants. J. Appl. Phycol. 28, 2549-2560. doi: 10.1007/s10811-015-0781-4

Hong, D. D., Hien, H. M., and Son, P. N. (2007). Seaweeds from Vietnam used for functional food, medicine and fertilizer. J. Appl. Phycol. 19, 817-826 doi: 10.1007/s10811-007-9228-x

Joubert, J. M., and Lefranc, G. (2008). Seaweed biostimulants in agriculture: recent studies on mode of action two types of products from alga: growth and nutrition stimulants and stimulants of plant Demence reactions. Book of abstracts: Biostimulants in modern agriculture. Warsaw, 16.

Junge, W., and Klees, H. (1984). "Peroxidases," in Methods of Enzymatic Analysis $I V$, ed H. V. Bergmeyer, 3rd Edn (New York, NY: Academic Press), 8-14.

Khan, W., Rayirath, U. P., Subramanian, S., Jithesh, M. N., Hodges, D. M., Critchley, A. T., et al. (2009). Seaweed extracts as biostimulants of plant growth and development. Plant Growth Regul. 28, 386-399. doi: 10.1007/s00344-009-9103-x

Krsnik-Rasol, M., Cipcic, H., and Hagege, D. (1999). Isoesterases related to cell differentiation in plant tissue culture. Chemico-Biol. Interact. 120, 587-592. doi: 10.1016/S0009-2797(99)00073-3

Leal, D., Matsuhiro, B., Rossi, M., and Caruso, F. (2008). FT-IR spectra of alginic acid block fractions in three species of brown seaweeds. Carbohydr. Res. 343, 308-316. doi: 10.1016/j.carres.2007.10.016
Lüthje, S., and Böttger, M. (1995). On the function of a K-type vitamin in plasma membranes of maize (Zea mays L.) roots. Mitt. Inst. Allg. Bot. Hamburg 25, 5-13.

MacKinnon, S. L., Hiltz, D., Ugarte, R., and Craft, C. A. (2010). Improved methods of analysis for betaines in Ascophyllum nodosum and its commercial seaweed extracts. Appl. Phycol. 22, 489-494. doi: 10.1007/s10811-009-9483-0

Mathlouthi, M., and Koenig, J. L. (1986). Vibrational spectra of carbohydrates. Adv. Carbohydr. Chem. Biochem. 44, 7-66. doi: 10.1016/S0065-2318(08)60077-3

Mancuso, S., Azzarello, E., Mugnai, S., and Briand, X. (2006). Marine bioactive substances (IPA extract) improve foliar ion uptake and water stress tolerance in potted Vitis vinifera plants. Adv. Hortic. Sci. 20, 156-161.

Marinval, N., Saboural, P., Haddad, O., Maire, M., Bassand, K., Geinguenaud, F., et al. (2016). Identification of a pro-angiogenic potential and cellular uptake mechanism of a LMW highly sulfated fraction of fucoidan from Ascophyllum nodosum. Mar. Drugs 14:185. doi: 10.3390/md14100185

Michalak, I., Choinacka, K., Dmytryk, A., Wilk, R., Gramza, M., and Rój, E. (2016). Evaluation of supercritical extracts of algae as biostimulants of plant growth in field trials. Front. Plant Sci. 7:1591. doi: 10.3389/fpls.2016. 01591

Mugnai, S., Azzarello, E., Pandolfi, C., Salamagne, S., Briand, X., and Mancuso, S. (2008). Enhancement of ammonium and potassium root influxes by the application of marine bioactive substances positively affects Vitis vinifera plant growth. J. Appl. Phycol. 20, 177-182. doi: 10.1007/s10811-007-9 203-6

Muscolo, A., Sidari, M., and da Silva, J. A. T. (2013). Biological effects of watersoluble soil phenol and soil humic extracts on plant systems. Acta Physiol. Plant 35, 309-320. doi: 10.1007/s11738-012-1065-0

Nardi, S., Pizzeghello, D., Gessa, C., Ferrarese, L., Trainotti, L., and Casadoro, A. (2000). Low molecular weight humic fraction on nitrate protein synthesis in maize seedlings. Soil. Biol. Biochem. 32, 415-419. doi: 10.1016/S0038-0717(99)00168-6

Nardi, S., Pizzeghello, D., Schiavon, M., and Ertani, A. (2016). Plant biostimulants: physiological responses induced by protein hydrolyzed-based products and humic substances in plant metabolism. Sci. Agric. 73, 18-23. doi: 10.1590/0103-9016-2015-0006

Pedersen, S., and Andersen, S. B. (1993). Developmental expression of isoenzymes during embryiogenesis in barley anther culture. Plant Sci. 91, 75-86 doi: 10.1016/0168-9452(93)90190-B

Pereira, L., Amado, A. M., Critchley, A. T., van de Velde, F., and Ribeiro-Claro, P. J. A. (2009). Identification of selected seaweed polysaccharides (phycocolloids) by vibrational spectroscopy (FTIR-ATR and FT-Raman). Food Hydrocoll. 23, 1903-1909. doi: 10.1016/j.foodhyd.2008.11.014

Pereira, L., Gheda, S. F., and Ribeiro-Claro, P. J. A. (2013). Analysis by vibrational spectroscopy of seaweed polysaccharides with potential use in food, pharmaceutical, and cosmetic industries. Int. J. Carbohydr. Chem. 2013:7. doi: $10.1155 / 2013 / 537202$

Prithiviraj, B. (2008). Rapid bioassays to evaluate the plant growth promoting activity of Ascophyllum nodosum (L.) Le Jol. using a model plant, Arabidopsis thaliana (L.) Heynh. J. Appl. Phycol. 20, 423-429 doi: 10.1007/s10811-007-9280-6

Rengasamy, K. R. R., Kulkarni, M. G., Stirk, W. A., and Van Staden, J. (2015). A new plant growth stimulant from the brown seaweed Ecklonia maxima. J. Appl. Phycol. 27, 581-587. doi: 10.1007/s10811-014-0337-z

Rosa, M., Prado, C., Podazza, G., Interdonato, R., González, J. A., Hilal, M., et al. (2009). Soluble sugars - metabolism, sensing and abiotic stress A complex network in the life of plants. Plant Signal Behav. 4, 388-393. doi: 10.4161/psb.4.5.8294

Roussos, P. A., Denaxa, N. K., and Damvakaris, T. (2009). Strawberry fruit quality attributes after application of plant growth stimulating compounds. Sci. Hortic. 119, 138-146. doi: 10.1016/j.scienta.2008.07.021

Satish, L., Ceasar, S. A., Shilpha, J., Rency, S. A., Rathinapriya, P., and Ramesh, M. (2015). Direct plant regeneration from in vitro-derived shoot apical meristems of finger millet (Eleusine coracana (L.) Gaertn.). In Vitro Cell Dev. Biol. Plant. 51, 192-200. doi: 10.1007/s11627-015-9672-2

Schiavon, M., Pizzeghello, D., Muscolo, A., Vaccaro, S., Francioso, O., and Nardi, S. (2010). High molecular size humic substances enhance phenylpropanoid metabolism in Maize (Zea mays L.) J. Chem. Ecol. 36, 662-669. doi: 10.1007/s10886-010-9790-6 
Santaniello, A., Scartazza, A., Gresta, F., Loreti, E., Biasone, A., Di Tommaso, D., et al. (2017). Ascophyllum nodosum seaweed extract alleviates drought stress in Arabidopsis by affecting photosynthetic performance and related gene expression. Front. Plant Sci. 8:1362. doi: 10.3389/fpls.2017.01362

Sharma, H. S. S., Fleming, C., Selby, C., Rao, J. R., and Martin, T. (2014). Plant biostimulants: a review on the processing of macroalgae and use of extracts for crop management to reduce abiotic and biotic stresses. J. Appl. Phycol. 26, 465-490. doi: 10.1007/s10811-013-0101-9

Sivasankari, S., Venkatesalu, V., Anantharaj, M., and Chandrasekaran, M. (2006). Effect of seaweed extracts on the growth and biochemical constituents of Vigna sinensis. Bioresour. Technol. 97, 1745-1751. doi: 10.1016/j.biortech.2005.06.016

Spinelli, F., Fiori, G., Noferini, M., Sprocatti, M., and Costa, G. (2010). A novel type of seaweed extract as a natural alternative to the use of iron chelates in strawberry production. Sci Hortic. 125, 263-269. doi: 10.1016/j.scienta.2010.03.011

Synytsya, A., Bleha, R., Synytsya, A., Pohl, R., Hayashi, K., Yoshinaga, K., et al. (2014). Mekabu fucoidan: structural complexity and defensive effects against avian influenza A viruses. Carbohydr. Polym. 111, 633-644. doi: 10.1016/j.carbpol.2014.05.032
Thaker, V. S., Saroop, S., Vaishnav, P. P., and Singh, Y. D. (1986). Role of peroxidase and esterase activities during cotton fiber development. J. Plant Growth Regul. 5, 17-27. doi: 10.1007/BF02027383

Yang, L., and Zhang, L. M. (2009). Chemical structural and chain conformational characterization of some bioactive polysaccharides isolated from natural sources. Carbohydr. Polym. 76, 349-361 doi: 10.1016/j.carbpol.2008. 12.015

Conflict of Interest Statement: The authors declare that the research was conducted in the absence of any commercial or financial relationships that could be construed as a potential conflict of interest.

Copyright (c) 2018 Ertani, Francioso, Tinti, Schiavon, Pizzeghello and Nardi. This is an open-access article distributed under the terms of the Creative Commons Attribution License (CC BY). The use, distribution or reproduction in other forums is permitted, provided the original author(s) and the copyright owner are credited and that the original publication in this journal is cited, in accordance with accepted academic practice. No use, distribution or reproduction is permitted which does not comply with these terms. 